\title{
Persistent domestic circulation of African swine fever virus in Tanzania, 2015-2017
}

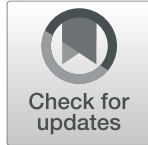

Clara M. Yona ${ }^{1,2}$, Merijn Vanhee ${ }^{3}$, Edgar Simulundu ${ }^{4}$, Mariam Makange ${ }^{5}$, Hans J. Nauwynck ${ }^{6}$ and Gerald Misinzo ${ }^{1,5^{*}}$

\begin{abstract}
Background: African swine fever (ASF) is a highly fatal viral hemorrhagic disease of domestic pigs that threatens livelihoods and food security. In Africa, ASF virus (ASFV) circulates in sylvatic (transmission between warthogs and soft argasid ticks) and domestic (transmission between domestic pigs) cycles, with outbreaks resulting from ASFV spill-over from sylvatic cycle. A number of outbreaks were reported in different parts of Tanzania between 2015 and 2017. The present study investigated ASFV transmission patterns through viral DNA sequencing and phylogenetic analysis. A total of 3120 tissue samples were collected from 2396 domestic pigs during outbreaks at different locations in Tanzania between 2015 and 2017. Partial sequencing of the B646L (p72) gene was conducted for diagnostic confirmation and molecular characterization of ASFV. Phylogenetic analysis to study the relatedness of current ASFV with those that caused previous outbreaks in Tanzania and representatives of all known 24 ASFV was performed using the Maximum Composite Likelihood model with 1000 bootstrap replications in MEGA 6.0.

Results: ASFV was confirmed to cause disease in sampled domestic pigs. ASFV genotypes II, IX, and X were detected from reported outbreaks in 2015-2017. The current ASFV isolates were similar to those recently documented in the previous studies in Tanzania. The similarities of these isolates suggests for continuous circulation of ASFV with virus maintenance within the domestic pigs.

Conclusions: Genetic analysis confirmed the circulation of ASFV genotypes II, IX, and X by partial B646L (p72) gene sequencing. The similarities of current isolates to previously isolated Tanzanian isolates and pattern of disease spread suggest for continuous circulation of ASF with virus' maintenance in the domestic pigs. Although certain viral genotypes seem to be geographically restricted into certain zones within Tanzania, genotype II seems to expand its geographical range northwards with the likelihood of spreading to other states of the East African Community. The spread of ASFV is due to breach of quarantine and transportation of infected pigs via major highways. Appropriate control measures including zoosanitary measures and quarantine enforcement are recommended to prevent ASF domestic circulation in Tanzania.
\end{abstract}

Keywords: African swine fever, African swine fever virus, Asfarviridae, genotype, Sus scrofa, Tanzania

\footnotetext{
* Correspondence: gerald.misinzo@sacids.org

${ }^{1}$ SACIDS Foundation for One Health, SACIDS Africa Centre of Excellence for Infectious Diseases, Sokoine University of Agriculture, Morogoro, Tanzania ${ }^{5}$ Department of Veterinary Microbiology, Parasitology and Biotechnology, College of Veterinary Medicine and Biomedical Sciences, Sokoine University of Agriculture, Morogoro, Tanzania

Full list of author information is available at the end of the article
}

(c) The Author(s). 2020 Open Access This article is licensed under a Creative Commons Attribution 4.0 International License, which permits use, sharing, adaptation, distribution and reproduction in any medium or format, as long as you give appropriate credit to the original author(s) and the source, provide a link to the Creative Commons licence, and indicate if changes were made. The images or other third party material in this article are included in the article's Creative Commons licence, unless indicated otherwise in a credit line to the material. If material is not included in the article's Creative Commons licence and your intended use is not permitted by statutory regulation or exceeds the permitted use, you will need to obtain permission directly from the copyright holder. To view a copy of this licence, visit http://creativecommons.org/licenses/by/4.0/ The Creative Commons Public Domain Dedication waiver (http://creativecommons.org/publicdomain/zero/1.0/) applies to the data made available in this article, unless otherwise stated in a credit line to the data. 


\section{Background}

African swine fever (ASF) is a contagious viral hemorrhagic disease of pigs affecting domestic pigs and wild pigs [1]. African swine fever is endemic in subSaharan countries and the mortality rates can reach up to $100 \%$ [2]. African swine fever is caused by ASF virus (ASFV), a DNA arbovirus belonging to the Asfivirus genus and a sole member of the Asfarviridae family [3]. The ASFV virion is enveloped, has an icosahedral morphology and contains a double-stranded DNA genome whose size ranges between 170 and 193 kilo base pairs depending on the isolate [4]. Warthogs are reservoir hosts that are persistently infected with no obvious clinical disease, and soft ticks of the genus Ornithodoros act as vectors of ASFV and contribute to viral maintenance within the sylvatic cycle as well as in transmitting the virus to domestic pigs [5]. Transmission of ASFV from the sylvatic cycle to domestic pigs occurs through a tick bite, feeding contaminated warthog carcasses to domestic pigs and/or contact with warthog faeces [6]. Once ASFV is transmitted to domestic pigs, the virus spreads between domestic pigs through contact between infected and susceptible pigs, feeding pigs with meat or via fomites such as contaminated clothing, shoes, equipment and vehicles [7].

The existence of the sylvatic cycle contributes to a rich genetic diversity of ASFV. Based on partial amplification and sequence analysis of the p72 (B646L) gene, 24 genotypes of ASFV have been identified [8-10]. All of the 24 ASFV genotypes have been described in African countries, South of the Sahara, 23 of which are currently restricted to Eastern and Southern Africa [2, 9]. Genotypes I, II and IX of ASFV have been reported to spread beyond their traditional geographical range. For instance, genotype I spread from West Africa to Europe, South America and the Caribbean [11]. On the other hand, genotype II, which was known to circulate in Zambia, Malawi, and Mozambique, spread to the Caucasus and afterward to the European Union, Russia and China [12-16]. Furthermore, genotype II ASFV has been introduced to Tanzania and Zimbabwe, where it was never known to circulate $[17,18]$. Similarly, genotype IX which is restricted to Eastern Africa has been reported to spread to Western Africa [19].

The spread of ASFV beyond African countries south of the Sahara and its traditional geographical boundaries poses a threat to the global pig industry, international trade market and food security. In 2018, the ASFV spread to China, a major pork producer, and afterward, the virus has spread to Asian countries including Mongolia, Vietnam, Indonesia, Democratic People's Republic of Korea, Lao People's Democratic Republic, Myanmar, The Philippines, Republic of Korea, TimorLeste and Cambodia [14-16].
A number of sporadic ASF outbreaks have been reported since 2000 in different parts of Tanzania, associated with ASFV genotypes II, IX, X, XV and XVI [17, 20-23]. There appears to be a geographical restriction of the ASFV genotypes in Tanzania with genotype II being restricted to Southwestern Tanzania, genotype IX to Northwestern Tanzania, genotypes $\mathrm{X}$ and XVI to Northeastern Tanzania and genotype XV to Eastern Tanzania [17, 20-22, 24]. These outbreaks in other parts of Tanzania end up in Dar es Salaam due to the transportation of infected pigs for sale and slaughter from other parts of the country to this main commercial capital [20, 21]. Many outbreaks have been reported in different parts of Tanzania between 2010 and 2017. The aim of this study was to investigate the ASFV transmission patterns through virus genotyping in order to understand the relationship between ASF outbreaks.

\section{Results}

\section{Clinical signs and postmortem findings}

Clinical signs observed in sick pigs included a high fever $\left(>40{ }^{\circ} \mathrm{C}\right.$ ), anorexia, staggering gait, shivering and cutaneous congestion particularly on the outer side of the pinna, belly, limbs and genitalia (Fig. 1a). Pigs were dull and stayed together at one side of their pens (Fig. 1b). Abortion was observed in pregnant sows. At postmortem, the pericardial and thoracic cavities were filled with straw tinged fluid (Fig. 1c). In addition, postmortem findings included hemorrhages in the spleen, heart, kidneys and lymph nodes especially the gastrohepatic, thoracic, mesenteric and renal lymph nodes (Fig. 1d and f). Splenomegaly (enlargement of the spleen) and enteritis were also observed (Fig. 1e).

\section{Confirmatory diagnosis of ASFV}

In total, 3120 tissues samples collected from different parts of Tanzania were screened using ASF diagnostic PCR. Analysis of collected tissue samples confirmed the presence of ASFV in 2170 tissue samples (Table 1). The PCR products of ASFV nucleic acid with a band size of 257 base pairs using primers PPA1 and PPA2 were obtained.

\section{Molecular characterization of ASFV}

A phylogenetic tree was constructed by the NeighborJoining method in order to determine the genetic relationship between the ASFV strains collected during 2015 and 2017 outbreaks, and previously sequenced Tanzanian ASFV strains available in GenBank (Fig. 2). The ASFV strains collected during this study (accession numbers MF437289 - MF437310) clustered with p72 genotypes II, IX and X (Fig. 2). Genotype II ASFV strains were characterized from Southwestern, Central and 


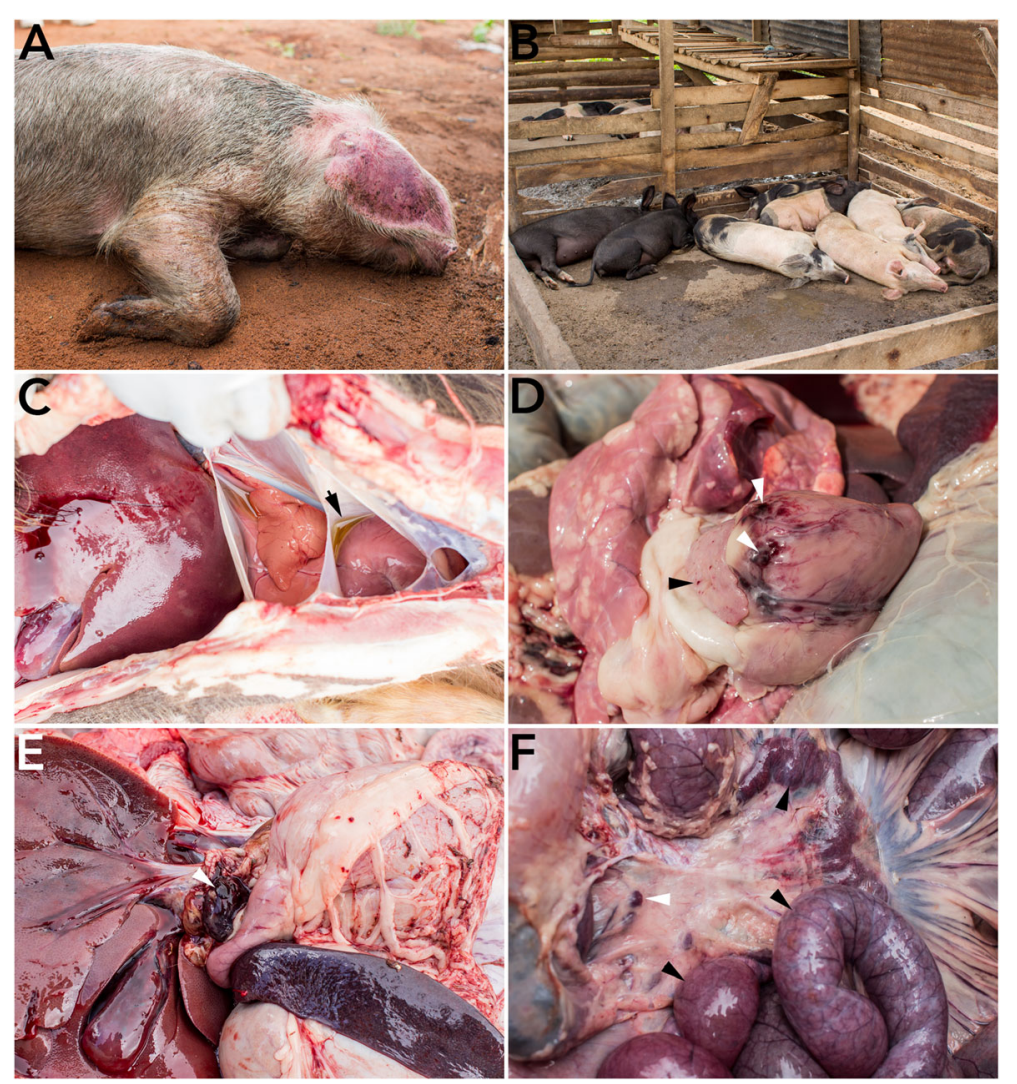

Fig. 1 Clinical signs and postmortem findings observed in domestic pigs with African swine fever. a Ventral recumbence and cutaneous congestion especially on the outer side of pinna and $\mathbf{b}$ loss of appetite, lateral recumbence and a tendency to stay together at one side of the pen were observed in pigs with African swine fever. At postmortem, $\mathbf{c}$ the pericardial and thoracic cavities were filled with straw tinged fluid (indicated by an arrow), $\mathbf{d}$ hemorrhages of the heart (indicated by an arrow) especially at the atrioventricular junctions, e hemorrhages of the gastrohepatic lymph node (indicated by an arrow) and $\mathbf{f}$ enteritis and hemorrhages of the mesenteric lymph nodes (indicated by an arrow head)

Eastern Tanzania, genotype IX from Northwestern parts of Tanzania around Lake Victoria and genotype X from Northwestern, Northeastern and Central parts of Tanzania (Fig. 4). The ASFV collected from outbreaks between 2015 and 2017 clustered into genotype II, IX and $\mathrm{X}$ along with ASFV that were responsible for previous outbreaks in Africa, Europe and Asia (Fig. 3).

\section{Discussion}

Several outbreaks of a highly fatal hemorrhagic disease affecting domestic pigs, suspected to be ASF based on clinical signs and postmortem findings, were reported in different parts of Tanzania between 2015 and 2017. ASF remains a major constraints to the pig industry in Tanzania with reported outbreaks throughout the year. There is neither a cure nor vaccine to prevent ASF infection. The control and eradication measures of ASF are based on surveillance, epidemiological investigation, animal movement control, quarantine and zoosanitary measures. Early detection of the disease and its spread is important for a successful surveillance and accurate diagnostic procedures are important for effective quarantine and control measures [25]. In this study, molecular methods were used to identify and characterize ASFV from domestic pigs that died of hemorrhagic disease outbreaks in Tanzania.

The results obtained in the 2015-2017 outbreaks confirm ASF outbreaks in domestic pigs in the studied areas. In the present study, these ASF outbreaks were confirmed to be caused by ASFV belonging to genotypes II, IX and X (Figs. 2 and 3). Prior to 2015, the ASFV that caused ASF outbreaks in Tanzania clustered into genotypes II, IX, X, XV and XVI (Table 2) [20, 22-24]. The recent ASF outbreaks were caused by ASFV that were $100 \%$ genetically identical to previously reported viruses, for each of the genotype II, IX and X (Fig. 2). The identity of ASFV between previous and recent outbreaks and the pattern of disease spread strongly indicate domestic pig-to-pig transmission.

Prior to 2015, genotype II ASFV were reported during outbreaks in Southwestern and Eastern parts of 


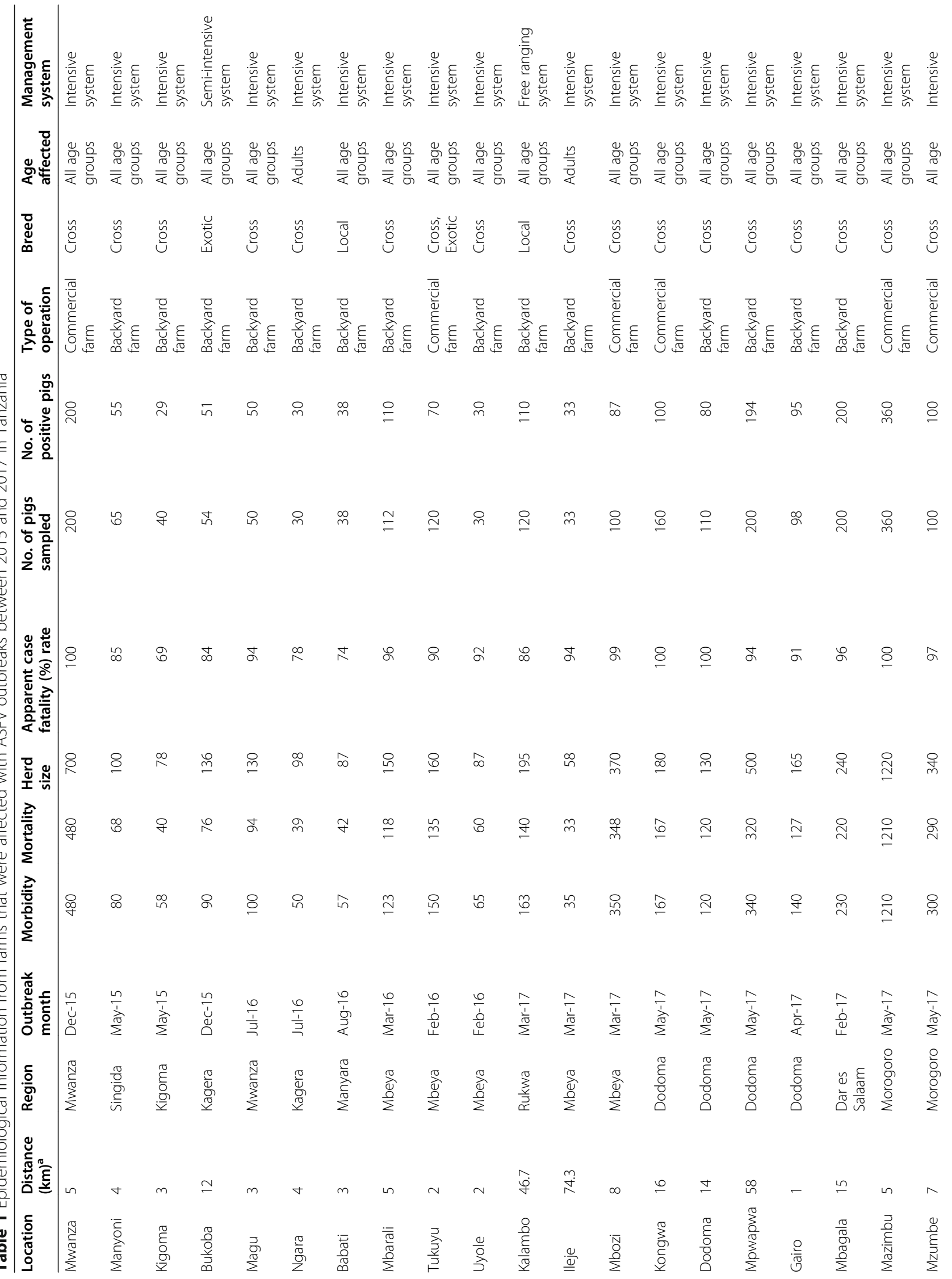




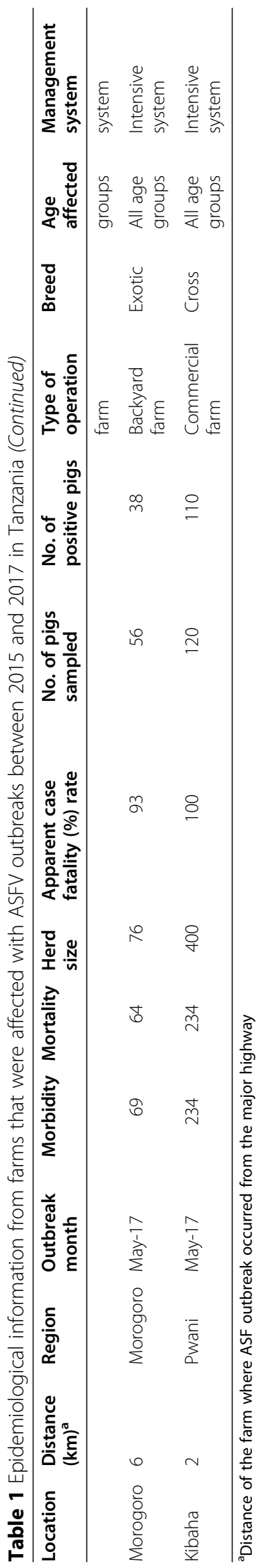




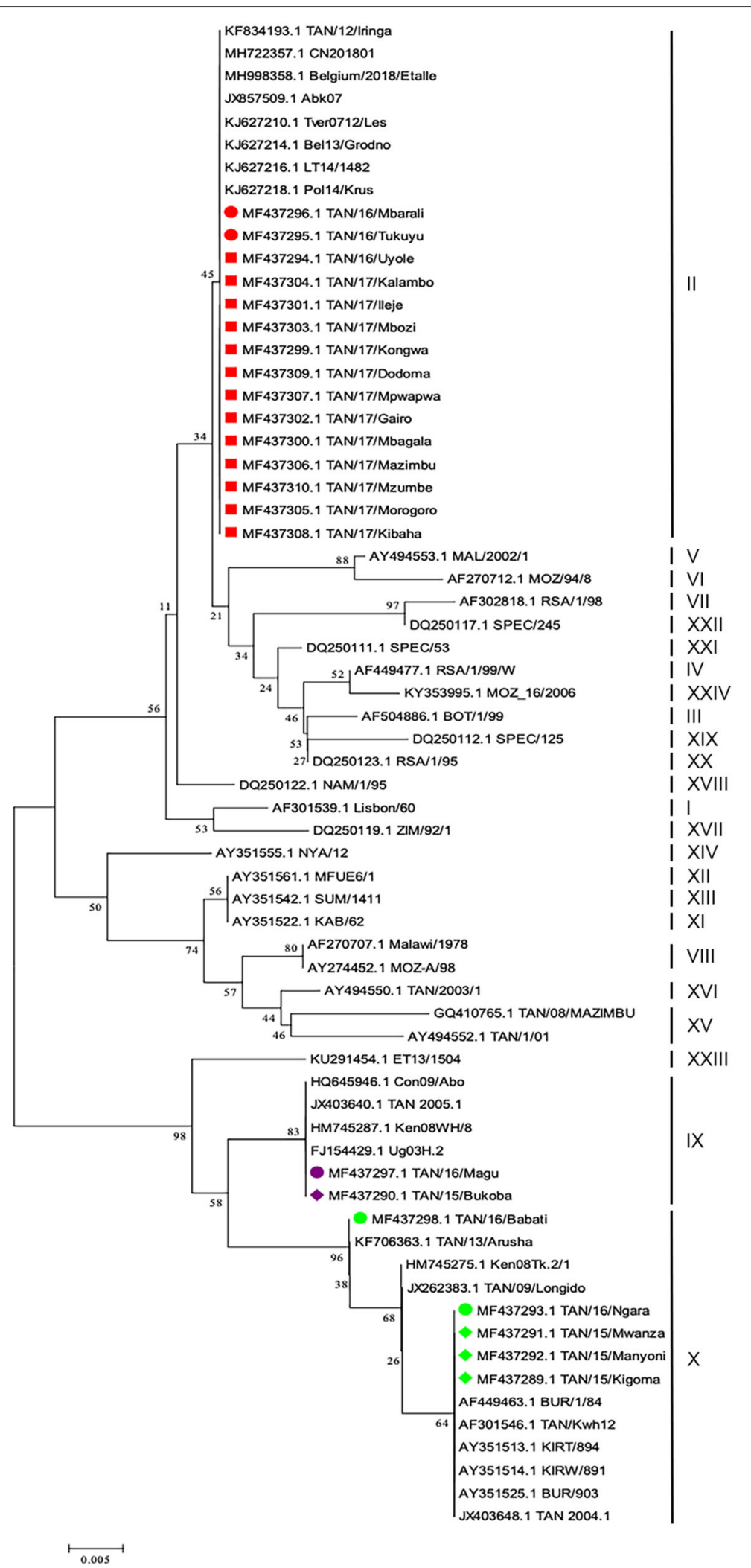

Fig. 2 (See legend on next page.) 
(See figure on previous page.)

Fig. 2 Phylogenetic relationship of African swine fever viruses (ASFV). The ASFV which were collected in the present study and from 2015 to 2017 are indicated by square, circle and diamond, respectively. Genotype II, IX, X, XV and XVI are labeled in red, purple, green, blue and pink respectively. Phylogeny was inferred following 1,000 bootstrap replications and node values show percentage bootstrap support. Scale bar indicates nucleotide substitution per site. The GenBank accession numbers for the different B646L (p72) gene are indicated in parenthesis

Tanzania (Figs. 2 and 4) [17]. Genotype II ASFV is thought to have been introduced into Tanzania in Kyela, a town in Southwestern Tanzania at the Tanzania Malawi border following an outbreak in Karonga in 2010 [17]. Since the introduction of genotype II ASFV, the virus spread within Southwestern parts of the country with occasional incursion into Eastern Tanzania [17]. In the present study, we found that genotype II ASFV continued to circulate in previously reported areas and it spread into new areas of Central Tanzania (Fig. 4). Previously, ASF outbreaks in Eastern Tanzania were linked to outbreaks in Southwestern Tanzania due to transportation of live pigs for sale in the main commercial city of
Dar es Salaam [17]. The Southwestern part of the country is linked to Dar es Salaam by a major highway from Sumbawanga via Tunduma, Mbeya, Iringa and Morogoro (Fig. 4). Furthermore, the different ASF outbreaks between 2015 and 2017 due to genotype II ASFV occurred in various locations along and in the vicinity of the Morogoro - Dodoma highway, which branches off in Morogoro from the Tunduma - Dar es Salaam highway. The outbreaks involving genotype II ASFV seem to have originated from Southwestern Tanzania (Mbeya and Rukwa regions) before spreading to Dar es Salaam, Morogoro, Dodoma and Pwani regions in the vicinity of major highways. The spread of the virus along these

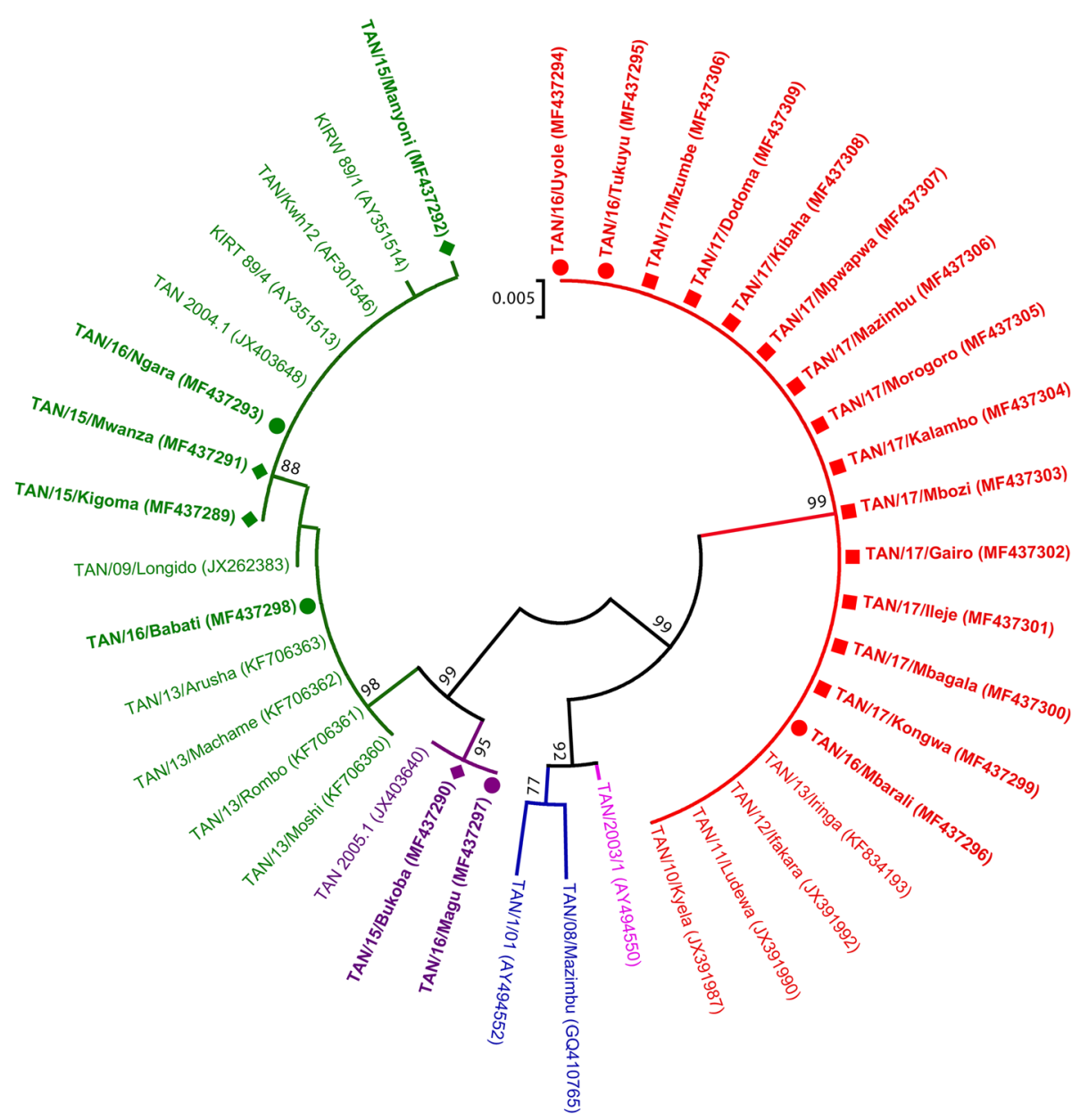

Fig. 3 Neigbour joining phylogenetic tree of the partial B646L (p72) gene of Tanzanian ASFV isolates of 2015-2017 relative to representatives of all known 24 p72 genotypes indicated as I - XXIV. The evolutionary history was inferred by the Maximum Composite Likelihood model with 1000 replicates boostrap analysis. ASFV Tanzania isolates characterized in this study are marked in red, purple and green for genotype II, IX and X respectively with the square, circle and diamond signs for 2015, 2016 and 2017 
Table 2 List of the representative of all 24 known ASFV isolates from different locations and isolates characterized from this study used and ASFV genetically characterized in the present study based on partial B646L (p72) genotypes for evolutionary analysis

\begin{tabular}{|c|c|c|c|c|c|c|c|}
\hline $\begin{array}{l}\text { Host } \\
\text { species }\end{array}$ & Isolate & $\begin{array}{l}\text { Year of } \\
\text { Isolation }\end{array}$ & Town/District & Country & $\begin{array}{l}\text { GenBank Accession } \\
\text { number }\end{array}$ & $\begin{array}{l}\text { p72 } \\
\text { genotype }\end{array}$ & Reference \\
\hline Pig & TAN/10/Kyela & 2010 & Kyela & Tanzania & JX391987 & $\|$ & {$[17]$} \\
\hline Pig & TAN/11/Ludewa & 2011 & Ludewa & Tanzania & JX391990 & $\|$ & {$[17]$} \\
\hline Pig & TAN/12/Ifakara & 2012 & Ifakara & Tanzania & JX391992 & $\|$ & [17] \\
\hline Pig & TAN/13/Iringa & 2013 & Iringa & Tanzania & KF834193 & $\|$ & Unpublished \\
\hline $\mathrm{DP}$ & CN201801 & 2018 & Shenbei & China & MH722357 & $\|$ & {$[15]$} \\
\hline WB & $\begin{array}{l}\text { Belgium/2018/ } \\
\text { Etalle }\end{array}$ & 2018 & Etalle & Belgium & MH998358 & $\|$ & [26] \\
\hline $\mathrm{DP}$ & Abk07 & 2007 & Gulripish & Georgia & JX857509 & $\|$ & [13] \\
\hline $\mathrm{DP}$ & Tver0712/Les & 2012 & Lesnoi & Russia & KJ627210 & $\|$ & [13] \\
\hline $\mathrm{DP}$ & Bel13/Grodno & 2013 & Grodno & Belarus & KJ627214 & $\|$ & [13] \\
\hline EWB & LT14/1482 & 2014 & Alytus County & Lithuania & KJ627216 & $\|$ & [13] \\
\hline EWB & Pol14/Krus & 2014 & Kruszyniany & Poland & KJ627218 & $\|$ & [13] \\
\hline $\mathrm{DP}$ & TAN/16/Mbarali & 2016 & Mbarali & Tanzania & MF437296 & $\|$ & This study \\
\hline $\mathrm{DP}$ & TAN/16/Tukuyu & 2016 & Tukuyu & Tanzania & MF437295 & $\|$ & This study \\
\hline $\mathrm{DP}$ & TAN/16/Uyole & 2016 & Uyole & Tanzania & MF437294 & $\|$ & This study \\
\hline $\mathrm{DP}$ & TAN/17/Kalambo & 2017 & Kalambo & Tanzania & MF437304 & $\|$ & This study \\
\hline $\mathrm{DP}$ & TAN/17/lleje & 2017 & Ileje & Tanzania & MF437301 & $\|$ & This study \\
\hline $\mathrm{DP}$ & TAN/17/Mbozi & 2017 & Mbozi & Tanzania & MF437303 & $\|$ & This study \\
\hline $\mathrm{DP}$ & TAN/17/Kongwa & 2017 & Kongwa & Tanzania & MF437299 & $\|$ & This study \\
\hline $\mathrm{DP}$ & TAN/17/Dodoma & 2017 & Dodoma & Tanzania & MF437309 & $\|$ & This study \\
\hline $\mathrm{DP}$ & $\begin{array}{l}\text { TAN/17/ } \\
\text { Mpwapwa }\end{array}$ & 2017 & Mpwapwa & Tanzania & MF437307 & $\|$ & This study \\
\hline DP & TAN/17/Gairo & 2017 & Gairo & Tanzania & MF437302 & $\|$ & This study \\
\hline DP & TAN/17/Mbagala & 2017 & Mbagala & Tanzania & MF437300 & $\|$ & This study \\
\hline $\mathrm{DP}$ & TAN/17/Mazimbu & 2017 & Mazimbu & Tanzania & MF437306 & $\|$ & This study \\
\hline $\mathrm{DP}$ & TAN/17/Mzumbe & 2017 & Mzumbe & Tanzania & MF437310 & $\|$ & This study \\
\hline $\mathrm{DP}$ & $\begin{array}{l}\text { TAN/17/ } \\
\text { Morogoro }\end{array}$ & 2017 & Morogoro & Tanzania & MF437305 & $\|$ & This study \\
\hline $\mathrm{DP}$ & TAN/17/Kibaha & 2017 & Kibaha & Tanzania & MF437308 & $\|$ & This study \\
\hline DP & TAN/15/Bukoba & 2015 & Bukoba & Tanzania & MF437290 & IX & This study \\
\hline $\mathrm{DP}$ & TAN/16/Magu & 2016 & Magu & Tanzania & MF437297 & IX & This study \\
\hline $\mathrm{DP}$ & Ug03H.2 & 2003 & Hoima & Uganda & FJ154429 & IX & {$[27]$} \\
\hline WH & Ken08WH/8 & 2008 & Machakos & Kenya & HM745287 & IX & [19] \\
\hline DP & CON09/Abo & 2009 & Abo, Cuvette & Rep. Congo & HQ645946 & IX & [19] \\
\hline DP & TAN 2005.1 & 2005 & Mwanza & Tanzania & $J X 403640$ & IX & Unpublished \\
\hline $\mathrm{DP}$ & TAN/16/Ngara & 2016 & Ngara & Tanzania & MF437293 & $x$ & This study \\
\hline $\mathrm{DP}$ & TAN/16/Babati & 2016 & Babati & Tanzania & MF437298 & $x$ & This study \\
\hline $\mathrm{DP}$ & TAN/15/Mwanza & 2015 & Mwanza & Tanzania & MF437291 & $x$ & This study \\
\hline $\mathrm{DP}$ & TAN/15/Manyoni & 2015 & Manyoni & Tanzania & MF437292 & $x$ & This study \\
\hline $\mathrm{DP}$ & TAN/15/Kigoma & 2015 & Kigoma & Tanzania & MF437289 & $x$ & This study \\
\hline $\mathrm{DP}$ & BUR/1/84 & 1984 & NK & Burundi & AF449463 & $x$ & [11] \\
\hline WH & TAN/Kwh12 & 1968 & $\begin{array}{l}\text { Serengeti National } \\
\text { Park }\end{array}$ & Tanzania & AF301546 & $x$ & [24] \\
\hline Tk & KIRT/894 & 1989 & Serengeti National & Tanzania & AY351513 & $x$ & {$[24]$} \\
\hline
\end{tabular}


Table 2 List of the representative of all 24 known ASFV isolates from different locations and isolates characterized from this study used and ASFV genetically characterized in the present study based on partial B646L (p72) genotypes for evolutionary analysis (Continued)

\begin{tabular}{|c|c|c|c|c|c|c|c|}
\hline $\begin{array}{l}\text { Host } \\
\text { species }\end{array}$ & Isolate & $\begin{array}{l}\text { Year of } \\
\text { Isolation }\end{array}$ & Town/District & Country & $\begin{array}{l}\text { GenBank Accession } \\
\text { number }\end{array}$ & $\begin{array}{l}\text { p72 } \\
\text { genotype }\end{array}$ & Reference \\
\hline & & & Park & & & & \\
\hline WH & KIRW/891 & 1989 & $\begin{array}{l}\text { Serengeti National } \\
\text { Park }\end{array}$ & Tanzania & AY351514 & $x$ & {$[24]$} \\
\hline $\mathrm{DP}$ & BUR/903 & 1990 & Muyinga & Burundi & AY351525 & $x$ & [24] \\
\hline Tk & Ken08Tk.2/1 & 2008 & Machakos & Kenya & HM745275 & $x$ & [19] \\
\hline Tk & TAN 2004.1 & 2004 & Kigoma & Tanzania & JX403648 & $x$ & Unpublished \\
\hline WH & TAN/09/Longido & 2009 & Longido & Tanzania & $J \times 262383$ & $x$ & [21] \\
\hline WH & TAN/13/Moshi & 2013 & Moshi & Tanzania & KF706360 & $x$ & [22] \\
\hline $\mathrm{DP}$ & TAN/13/Rombo & 2013 & Rombo & Tanzania & KF706361 & $x$ & [22] \\
\hline $\mathrm{DP}$ & TAN/13/Machame & 2013 & Machame & Tanzania & KF706362 & $x$ & [22] \\
\hline $\mathrm{DP}$ & TAN/13/Arusha & 2013 & Arusha & Tanzania & KF706363 & $x$ & [22] \\
\hline $\mathrm{DP}$ & TAN/08/Mazimbu & 2008 & Mazimbu & Tanzania & GQ410765 & $X V$ & {$[17]$} \\
\hline $\mathrm{DP}$ & $\operatorname{Tan} / 1 / 01$ & 2001 & Dar es Salaam & Tanzania & AY494552 & $X V$ & [24] \\
\hline $\mathrm{DP}$ & $\operatorname{Tan} / 2003 / 01$ & 2003 & Arusha & Tanzania & AY494550 & $X \mathrm{VI}$ & [24] \\
\hline $\mathrm{DP}$ & Lisbon/60 & 1960 & Lisbon & Portugal & AF301539 & । & [11 1] \\
\hline WH & ВОT/1/99 & 1999 & Sherwood & Botswana & AF504886 & III & [1 1 1 \\
\hline WH & RSA/1/99/W & 1999 & Thabazimbi & South Africa & AF449477 & IV & [11] \\
\hline $\mathrm{DP}$ & MAL/2002/1 & 2002 & Mpemba & Malawi & AY494553 & V & [24] \\
\hline DP & MOZ/94/8 & 1994 & Manica & Mozambique & AF270712 & $\mathrm{VI}$ & {$[28]$} \\
\hline $\mathrm{DP}$ & $\mathrm{RSA} / 1 / 98$ & 1998 & Potgietersrus & South Africa & AF302818 & VII & [28] \\
\hline $\mathrm{DP}$ & Malawi/1978 & 1978 & NK & Malawi & AF270707 & VIII & {$[28]$} \\
\hline $\mathrm{DP}$ & MOZ-A/98 & 1998 & Tete & Mozambique & AY274452 & VIII & [28] \\
\hline Tk & $\mathrm{KAB} / 62$ & 1983 & Livingstone & Zambia & AY351522 & $X I$ & [24] \\
\hline Tk & MFUE6/1 & 1982 & Mfue & Zambia & AY351561 & $X \|$ & [24] \\
\hline Tk & SUM/1411 & 1983 & Sumbu Park & Zambia & AY351542 & XIII & [24] \\
\hline Tk & NYA/12 & 1986 & Kalumo & Zambia & AY351555 & XIV & [24] \\
\hline $\mathrm{DP}$ & TAN/1/01 & 2001 & Dar es Salaam & Tanzania & AY494552 & $X V$ & [24] \\
\hline $\mathrm{DP}$ & TAN/2003/1 & 2003 & Arusha & Tanzania & AY494550 & $\mathrm{XVI}$ & [24] \\
\hline $\mathrm{DP}$ & ZIM/92/1a & 1992 & Gweru Midlands & Zimbabwe & DQ250119 & $X V I I$ & [8] \\
\hline $\mathrm{DP}$ & NAM/1/95 & 1995 & Windhoek & Namibia & DQ250122 & $X V I I I$ & {$[8]$} \\
\hline $\mathrm{DP}$ & SPEC/125 & 1987 & Ellisras & South Africa & DQ250112 & XIX & [8] \\
\hline $\mathrm{DP}$ & $\mathrm{RSA} / 1 / 95$ & 1995 & Hoiedspruit & South Africa & DQ250123 & $X X$ & [8] \\
\hline DP & SPEC/53 & 1985 & Letaba & South Africa & DQ250111 & $X X I$ & [8] \\
\hline DP & SPEC/245 & 1992 & Louis Trichardt & South Africa & DQ250117 & $X X I I$ & [8] \\
\hline DP & ET13/1504 & 2013 & Debre Zeit & Ethiopia & KU291454 & XXIII & [9] \\
\hline SF & MOZ_16/2006 & 2006 & $\begin{array}{l}\text { Gorongosa National } \\
\text { Park }\end{array}$ & Mozambique & KY353995 & XXIV & [10] \\
\hline
\end{tabular}

DP Domestic pigs, WB Wild boars, EWB European wild boars, WH Warthogs, SF Soft ticks, NK Not known

highways could be due to illegal transportation of infected domestic pigs from areas under quarantine, as described in previous reports [17, 20].

Genotype II ASFV is highly virulent and has been reported to spread beyond its traditional geographical boundaries of Malawi, Mozambique and Zambia into Madagascar, Mauritius, Zimbabwe, Tanzania, the Caucuses region, Russia, Europe and Asia [12, 14-16, 27, 29]. The 2015-2017 Tanzanian ASFV p72 genotype II isolates clustered with ASFV p72 genotype II isolates that have 


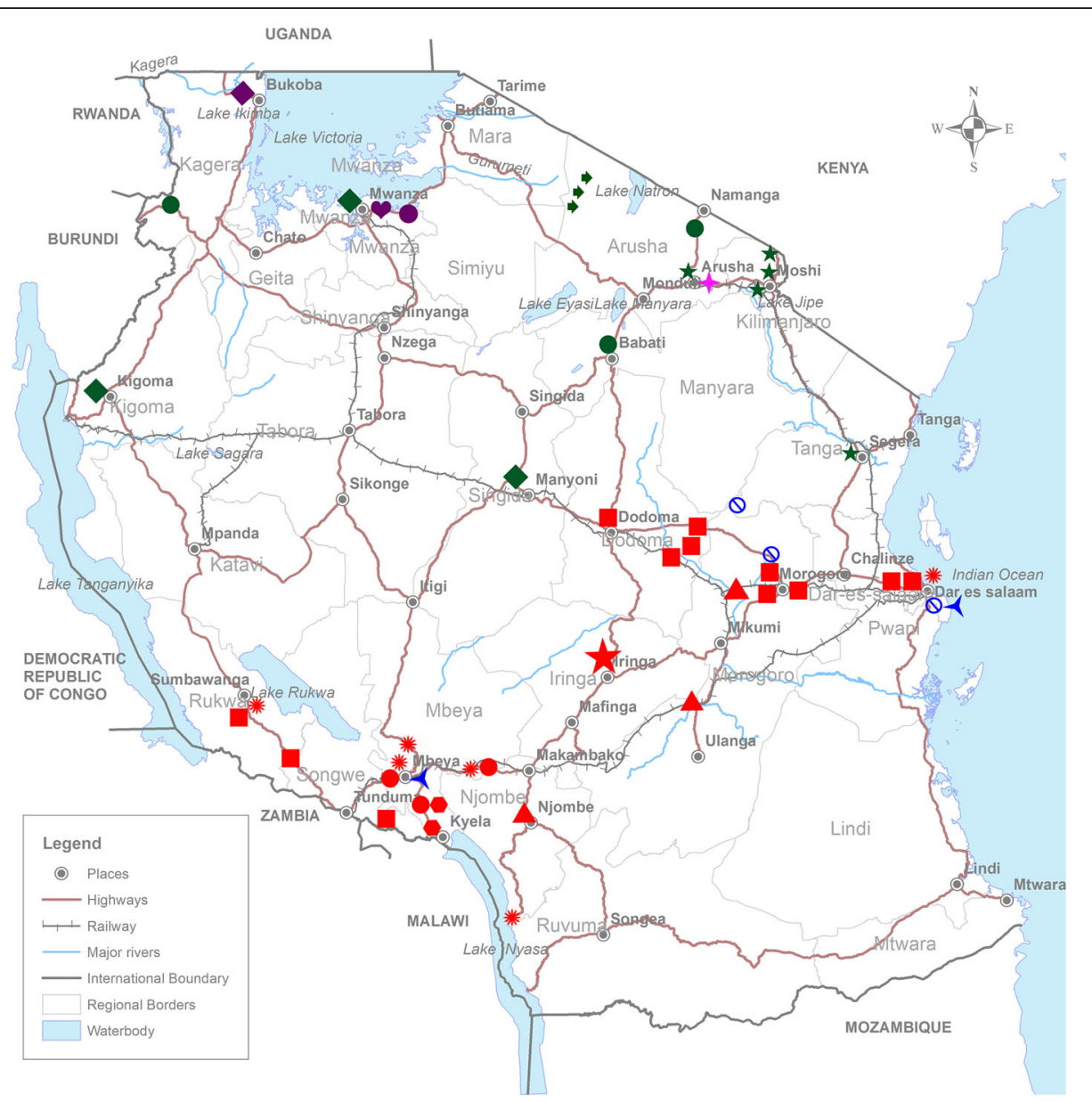

Fig. 4 Map of Tanzania showing reported African swine fever outbreaks and ASF virus (ASFV) genotypes between 2010 and 2017 . Africa swine fever outbreaks were reported in Southwestern, Eastern, Central, Northeastern and Northwestern Tanzania caused by ASFV genotypes II (red), IX (purple), X (green), XV (blue) and XVI (pink). The ASFV strains collected in Tanzania between 1968 and 2017 are indicated using different symbols;

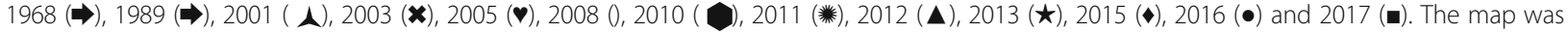
developed using QGIS version 3.4.4 (https://www.qgis.org/en/site/about/index.html). Afterwards, the symbols indicating ASF outbreak locations were added to the map using Adobe Photoshop CC 2017.0.0 Release, Adobe Systems Incorporated

been reported to cause outbreaks in Belgium (2018), Georgia (2007), Russia (2012), Belarus (2013), Lithuania (2014), Poland (2014) and China (2018) [13, 15, 26] (Fig. 3). If appropriate control measures of these genotype II viruses are not strictly enforced, we predict that this virus could possibly spread northwards and ultimately into bordering countries of Rwanda and Uganda, as these two countries are connected with Tanzania by major highways (Fig. 4). We recommend that stakeholders involved with ASF control be vigilant in order to prevent further spread of genotype II ASFV beyond Dodoma city, where it has reached.

In the present study, we found that ASFV genotype X circulated in Northeastern Tanzania, similar to other ASFV genotypes that have been previously described in the area $[17,22]$. In addition, we found that genotype $\mathrm{X}$ ASFV has spread into new areas within Central and
Western Tanzania (Fig. 4). The similarity of current ASFV to previously documented ASFV in Northeastern Tanzania indicates the continuous circulation of the virus with its maintainance in the domestic cycle. Additionally, phylogenetic analysis clustered current ASFV genotype $\mathrm{X}$ isolates with previously characterized ASFV isolates from Burundi (1999) and Kenya (2008) [11, 24]. The alignment of 404 nucleotide long sequence of the variable 3'-end of the B646L (p72) gene of ASFV Northeastern Tanzanian with 2008 ASFV outbreak in Kenya show only three nucleotide substitution $(\mathrm{A} \rightarrow \mathrm{T}, \mathrm{C} \rightarrow \mathrm{T}$, $A \rightarrow G)$ [19]. The Northern Tanzania is characterized with presence of wildlife protected areas. In East and Southern Africa, the ancient sylvatic cycle have been reported to play part in the epidemiology of the disease [5, 19, 24].

The ASFV genotype IX was confirmed to cause ASF outbreaks in Northwestern Tanzania. It was observed 
that ASFV genotype IX is restricted to Northwestern Tanzania, as it was $100 \%$ similar to ASFV isolates that caused ASF outbreaks in 2005 in Mwanza, Tanzania. Additionally, phylogenetic analysis revealed that the ASFV IX isolates were closely related to ASFV characterized in Uganda (2003), Kenya (2008) and Democratic Republic of Congo (2009) [19, 27]. ASFV sporadic outbreaks in Northwestern Tanzania is highly likely due to uncontrolled movement of pigs and pig products from affected areas to unaffected areas. However, studies that focus on ASF outbreaks investigation between neighboring countries should be encouraged for understanding the potential source of such viruses, variation and extent.

The isolation of ASFV from domestic pigs reports the circulation of these viral genotypes in the domestic pig population in Tanzania. However, this study points up for further isolation and epidemiological investigation in order to fully understand the variations, extent and potential sources of current ASF outbreaks in the region. The occurrence and spread of ASF between different parts of Tanzania is likely due to breach of quarantine imposed in areas affected with ASF. It is mostly likely that pig traders smuggle and transport pigs or pig meat from areas affected with ASF, where the prices are lower, into unaffected areas. Poor biosecurity measures in affected farms and slaughter slabs and swill feeding increase the likelihood of ASFV spread at a given locality, as has been previously described [17, 22]. Transportation of pig and pig products for regional market should be controlled to prevent ASFV spreading to other states of the East African Community, as ASFV genotype II has previously known to spread beyond its geographical range.

\section{Conclusions}

This study confirmed that ASFV genotype II, IX, and X were responsible for the reported outbreaks between 2015 and 2017. The similarities of the current Tanzanian ASFV isolates with those recently documented in the previous studies and pattern of spread in adjacent location during outbreaks suggest the continuous circulation of ASF with the virus's maintenance within the domestic cycle. Although certain viral genotypes seem to be geographically restricted into certain zones within Tanzania, genotype II seems to expand its geographical range northwards with the likelihood of spreading to other states of the East African Community. The spread of ASFV was mapped along major highways in Tanzania; this is likely due to the uncontrolled movement of pigs from affected to unaffected areas, breach of quarantine and poor zoosanitary measures. This study recommends continuous virus isolation and investigation to understand the epidemiology of ASFV in Tanzania and neighboring countries for local and inter-regional effective control and prevention interventions.

\section{Methods \\ Study area}

Samples were collected from domestic pigs following reports of suspected ASF outbreaks in different locations within Tanzania between 2015 and 2017. Samples were collected from Mwanza, Manyoni, Kigoma, and Bukoba districts in the year 2015, Babati, Ngara, Magu, Mbeya Municipality, Rungwe and Mbarali districts in the year 2016 and Kalambo, Ileje, Mbozi, Kongwa, Dodoma, Mpwapwa, Gairo, Mbagala, Mvomero, Morogoro Municipality and Kibaha districts in the year 2017 as indicated in Table 1.

\section{Sample collection and processing}

A total of 3120 tissue samples were collected from 2396 domestic pigs that died from a hemorrhagic disease typical of ASF. Epidemiological information from these farms with outbreaks were collected. Clinical observation of pigs was performed prior to sampling. Tissue samples including spleen, mesenteric lymph nodes, lungs and kidney were collected from dead domestic pigs from suspected ASF. Tissues were temporarily stored at $-20{ }^{\circ} \mathrm{C}$ before they were transported in ice cool boxes to the laboratory. Approximately, $1 \mathrm{~g}$ of each tissue sample was homogenized in $3 \mathrm{~mL}$ of sterile phosphate-buffered saline (PBS), followed by centrifugation of the homogenate at $6000 \mathrm{~g}$ for five minutes at $4{ }^{\circ} \mathrm{C}$. The tissue supernatant was transferred into a cryovial and stored at $-80{ }^{\circ} \mathrm{C}$ until DNA extraction.

\section{Detection of ASF in pig samples}

Aliquots $(100 \mu \mathrm{L})$ of each of the homogenized tissue samples from the same pig were pooled before conducting DNA extraction. DNA was extracted from the supernatant of pooled homogenized tissues using a QIAamp nucleic acid extraction kit (Qiagen, Hilden, Germany), following the manufacturer's instructions. The presence of ASFV DNA was detected by polymerase chain reaction (PCR) using the ASF diagnostic primer set PPA1 (5'-AGT TAT GGG AAA CCC GAC CC-3') and PPA2 (5'-CCC TGA ATC GGA GCA TCC T-3') that partially amplify the $B 646 L$ (p72) gene as previously described by Aguero et al. [30].

\section{Genetic characterization of ASFV}

Genetic characterization of ASFV was conducted in samples confirmed with ASFV by partial nucleotide amplification of the $B 646 L$ (p72) gene using primers p72U (5'-GGC ACA AGT TCG GAC ATG T-3') and p72D (5'-GTA CTG TAA CGC AGC ACA G-3') as previously described by Bastos et al. [11]. Afterwards, 
the PCR products were subjected to automated dideoxynucleotide cycle sequencing using BigDye Terminator Cycle sequencing kit version 3.1 (Applied Biosystems, Foster City, CA) and generated chromatograms were read by Sequence Scanner version 1.0 software (Applied Biosystems, Foster City, CA). The obtained nucleotide sequences were submitted to GenBank and were afterwards assigned with GenBank accession numbers (Table 2). The similarity search of the obtained nucleotide sequences against other ASFV sequences at GenBank database was performed using BLASTN version 2.6.0. The ASFV nucleotide sequences were aligned with previously characterized Tanzanian and global known 24 ASFV genotypes' nucleotide sequences available at GenBank using ClustalW. Phylogenetic analysis was performed using the Neighour-Joining method with 1000 bootstrap replications. The evolutionary history was inferred by the Maximum Composite Likelihood model using MEGA 6.0 [31].

\section{Acknowledgements}

We thank Dr. Emmanuel Swai (Directorate of Veterinary Services), Dr. Hilda Mrema (Tanzania Veterinary Laboratory Agency (TVLA), Iringa), Dr. Henry Kissinga (District Veterinary Officer (DVO), Sumbawanga), Dr. Petro Jacob Lema (DVO, Morogoro Municipality), Dr. Daniel Mdetele (Veterinary Investigation Centre (VIC), Dodoma), Dr. Kaini Kamwela (VIC, Sumbawanga), Dr. Fred Mlowe (DVO, lleje), Dr. Anthony Mwangolombe (Town Veterinary Officer, Njombe Town Council), Dr. Michael Madege (VIC, Mwanza), Dr. Obed N. Malangu (VIC, Arusha), Dr. Omari Nkullo (DVO, Kongwa) and Dr. Godbless E. Luhunga (DVO, Gairo) for their assistance in sample collection.

\section{Authors' contributions}

CMY participated in sample collection, methods, data analysis and development of manuscript. MM performed laboratory analysis. CMY, MV, GM and HJN conceived the idea, analysed, interpreted data and revised the manuscript. GM and HJN secured funding. GM and ES critically reviewed and edited the manuscript. All authors read and approved the final manuscript.

\section{Funding}

The study was funded by the Flemish Interuniversity Council (VLIR-UOS) through the ZEIN 2015 PR 409 TEAM 2015 project awarded to Ghent University and Sokoine University of Agriculture. The funder had no role in study design, data collection and analysis, decision to publish as well as in the preparation of this manuscript. The findings and conclusions of this study are those of the authors and do not necessarily represent the views of VLIR-UOS.

\section{Availability of data and materials}

The datasets generated and/or analysed during the current study are available at GenBank https://www.ncbi.nlm.nih.gov/popset/1463932638. The accession numbers are presented in Table 2.

\section{Ethics approval and consent to participate}

Ethical approval for animals sampling was sought from the Ethical Committee of Sokoine University of Agriculture. Written consent to participate was obtained from farmers and veterinarians before sampling of tissues from slaughtered pigs.

\section{Consent for publication}

All authors read and approved the final manuscript. Consent for publication has been obtained from all authors.

\section{Competing interests}

The authors declare that they have no competing interests.

\section{Author details}

${ }^{1}$ SACIDS Foundation for One Health, SACIDS Africa Centre of Excellence for Infectious Diseases, Sokoine University of Agriculture, Morogoro, Tanzania. ${ }^{2}$ Department of Biosciences, Solomon Mahlangu College of Science and Education, Sokoine University of Agriculture, Morogoro, Tanzania.

${ }^{3}$ Department of Biotechnology, VIVES University College, Roeselare, Belgium. ${ }^{4}$ Department of Disease Control, School of Veterinary Medicine, University of Zambia, Lusaka, Zambia. ${ }^{5}$ Department of Veterinary Microbiology,

Parasitology and Biotechnology, College of Veterinary Medicine and Biomedical Sciences, Sokoine University of Agriculture, Morogoro, Tanzania. ${ }^{6}$ Laboratory of Virology, Faculty of Veterinary Medicine, University of Gent, Merelbeke, Belgium.

Received: 21 September 2019 Accepted: 23 September 2020

Published online: 01 October 2020

\section{References}

1. Penrith M-L, Vosloo W, Jori F, Bastos ADS. African swine fever virus eradication in Africa. Virus Res [Internet]. 2013;173(1):228-46. Available from: http://www.sciencedirect.com/science/article/pii/S0168170212004005.

2. Costard S, Mur L, Lubroth J, Sanchez-Vizcaino JM, Pfeiffer DU. Epidemiology of African swine fever virus. Virus Res. 2013;Vol. 173:191-7.

3. Dixon LK, Alonso C, Escribano JM, Martins JM, Revilla Y, Salas ML, et al. Virus Taxonomy. In: Virus Taxonomy: Ninth Report of the International Committee on Taxonomy of Viruses. 2012 153-62.

4. de Villiers EP, Gallardo C, Arias M, da Silva M, Upton C, Martin R, et al. Phylogenomic analysis of 11 complete African swine fever virus genome sequences. Virology. 2010;400(1):128-36.

5. Jori F, Vial L, Penrith ML, Pérez-Sánchez R, Etter E, Albina E, et al. Review of the sylvatic cycle of African swine fever in sub-Saharan Africa and the Indian ocean. Virus Res. 2013;173(1):212-27.

6. Jori F, Bastos ADS. Role of wild suids in the epidemiology of African swine fever. Ecohealth. 2009;6:296-310

7. Mur L, Martínez-lópez B, Sánchez-vizcaíno JM. Risk of African swine fever introduction into the European Union through transport-associated routes: returning trucks and waste from international ships and planes. BMC Vet Res. 2012;8:149-61.

8. Boshoff $\mathrm{Cl}$, Gerber $\mathrm{L}$, Vosloo W. Genetic characterisation of African swine fever viruses from outbreaks in southern Africa (1973-1999). Vet Microbiol. 2007;6(1):45-55

9. Achenbach JE, Gallardo C, Nieto-Pelegrin E, Rivera-Arroyo B, Degefa-Negi M, Arias $M$. et. Identification of a new genotype of African swine fever virus in domestic pigs from Ethiopia. Transbound Emerg Dis. 2016;10:11111-2511.

10. Quembo CJ, Jori F, Vosloo W, Heath L. Genetic characterization of African swine fever virus isolates from soft ticks at the wildlife/domestic interface in Mozambique and identification of a novel genotype. Transbound Emerg Dis. 2018:65(2):420-31.

11. Bastos ADS, Penrith ML, Crucière C, Edrich JL, Hutchings G, Roger F, et al. Genotyping field strains of African swine fever virus by partial p72 gene characterisation. Arch Virol. 2003;148(4):693-706

12. Rowlands RJ, Michaud V, Heath L, Hutchings G, Oura C, Vosloo W, et al. African swine fever virus isolate, Georgia, 2007. Emerg Infect Dis. 2008; 14(12):1870-4.

13. Gallardo C, Fernández-Pinero J, Pelayo V, Gazaev I, Markowska-Daniel I, Pridotkas G, et al. Genetic variation among African swine fever genotype ॥ viruses, Eastern and Central Europe. Emerg Infect Dis. 2014;20(9):1544-7.

14. Li X, Tian K. African swine fever in China. Vet Rec. 2018;183(9):300.2-301.

15. Ge S, Li J, Fan X, Liu F, Li L, Wang Q, et al. Molecular characterization of African swine fever virus, China, 2018. Emerg Infect Dis. 2018;24(11):2131-3.

16. Zhou X, Li N, Luo Y, Liu Y, Miao F, Chen T, et al. Emergence of African Swine Fever in China, 2018. Transbound Emerg Dis. 2018;65(6):1482-4.

17. Misinzo G, Kasanga CJ, Mpelumbe-Ngeleja C, Masambu J, Kitambi A, Van Doorsselaere J. African swine fever virus, Tanzania, 2010-2012. Emerg Infect Dis. 2012;18(12):2081-3.

18. van Heerden J, Malan K, Gadaga BM, Spargo R. Reemergence of African swine fever in Zimbabwe, 2015. Emerg Infect Dis. 2017;23(5):860-1.

19. Gallardo C, Anchuelo R, Pelayo V, Poudevigne F, Leon T, Nzoussi J. et A. African swine fever virus p72 genotype IX in domestic pigs, Congo, 2009. Emerg Infect Dis. 2011;17(8):1556-8. 
20. Wambura PN, Masambu J, Msami H. Molecular diagnosis and epidemiology of African swine fever outbreaks in Tanzania. Vet Res Commun. 2006;30(6): 667-72.

21. Misinzo G, Magambo J, Masambu J, Yongolo MG, Van Doorsselaere J, Nauwynck HJ. Genetic characterization of African swine fever viruses from a 2008 outbreak in Tanzania. Transbound Emerg Dis. 2011;58(1):86-92.

22. Misinzo G, Kwavi DE, Sikombe CD, Makange M, Peter E, Muhairwa AP, et al. Molecular characterization of African swine fever virus from domestic pigs in northern Tanzania during an outbreak in 2013. Trop Anim Health Prod. 2014;46(7):1199-207.

23. Misinzo G, Jumapili F, Ludosha M, Mafie E, Silialis J, Mushi R, et al. Genotyping of African swine fever virus from a 2009 outbreak in Tanzania. Res Opin Anim Vet Sci. 2012;2(5):334-8.

24. Lubisi BA, Bastos AD, Dwarka RM, Vosloo W. Molecular epidemiology of African swine fever in East Africa. Arch Virol. 2005:150:2439-52.

25. Gallardo C, Nieto R, Soler A, Pelayo V, Fernández-Pinero J, Markowska-Daniel I, et al. Assessment of African swine fever diagnostic techniques as a response to the epidemic outbreaks in eastern european union countries: How to improve surveillance and control programs. J Clin Microbiol. 2015: 53(8):2555-65.

26. Garigliany M, Desmecht D, Tignon M, Cassart D, Lesenfant C, Paternostre J, et al. Phylogeographic analysis of African swine fever virus, Western Europe, 2018. Emerg Infect Dis. 2019;25(1):184-6.

27. Gallardo C, Mwaengo DM, MacHaria JM, Arias M, Taracha EA, Soler A, et al. Enhanced discrimination of African swine fever virus isolates through nucleotide sequencing of the p54, p72, and pB602L (CVR) genes. Virus Genes. 2009;38(1):85-95.

28. Bastos ADS, Penrith ML, Macome F, Pinto F, Thomson GR. Co-circulation of two genetically distinct viruses in an outbreak of African swine fever in Mozambique: No evidence for individual co-infection. Vet Microbiol. 2004; 103(3-4):169-82

29. Simulundu E, Chambaro HM, Sinkala Y, Kajihara M, Ogawa H, Mori A, et al. Co-circulation of multiple genotypes of African swine fever viruses among domestic pigs in Zambia (2013-2015). Transbound Emerg Dis. 2017;1-9.

30. Aguero M, Fernández J, Romero L, Mascaraque CS, Arias M, SánchezVizcaíno JM. Highly sensitive PCR assay for routine diagnosis of African swine fever virus in clinical samples. J Clin Microbiol. 2003:41(9):4431-4.

31. Tamura K, Stecher G, Peterson D, Filipski A, Kumar S. MEGA6: Molecular Evolutionary Genetics Analysis Version 6. 0. Mol Biol Evol. 2013;30(12):2725-9.

\section{Publisher's Note}

Springer Nature remains neutral with regard to jurisdictional claims in published maps and institutional affiliations.

Ready to submit your research? Choose BMC and benefit from:

- fast, convenient online submission

- thorough peer review by experienced researchers in your field

- rapid publication on acceptance

- support for research data, including large and complex data types

- gold Open Access which fosters wider collaboration and increased citations

- maximum visibility for your research: over $100 \mathrm{M}$ website views per year

At $\mathrm{BMC}$, research is always in progress.

Learn more biomedcentral.com/submissions 